\title{
NAILED MOMENT JOINTS IN TIMBER STRUCTURES
}

\author{
A.H. Bryant* , J.A. Gibson**, T.N. Mitchell***, S.J. Thurston****
}

\section{SYMOPSIS}

The development, design and testing of a nailed steel sideplate joint for the transfer of bending moments in timber structures is described.

\subsection{BACKGROUND}

This paper describes the development of a joint which is capable of transferring the full bending strength of one timber member to another. It is simple to design, fabricate and assemble, and may be readily used in the field.

This joint may be used in the assembly of large portal frame structures or multistorey bents comprising glued laminated or built up timber elements. Thus timber may now be used in a similar way to steel and reinforced concrete. Many buildings have been designed and constructed incorporating this joint and it is now considered to be an economical and predictable method of jointing timber elements.

\subsection{DESCRIPTION OF JOINT}

The joint comprises mild steel plates, generally between $3 \mathrm{~mm}$ and $6 \mathrm{~mm}$ in thickness, one each side of the members to be joined (Figs. 1 and 2). The plates contain predrilled holes set out in a rectangular ring pattern through which nails are driven into the timber members. The nails used are galvanised mild steel with either flat or round heads. The preferred penetration into the timber is 10 diameters, but many structures have been built after testing has indicated that lesser penetration is satisfactory e.g. bracket nail $30 \mathrm{~mm}$ long, $3.55 \mathrm{~mm}$ diameter nailed through $5 \mathrm{~mm}$ plate. Galvanised nails are preferred to minimise corrosion during construction and any possible long term corrosion.

To minimise slip between the plate and the timber the holes for the nails should provide a neat fit. Recommended hole diameter is $d+0.2 \mathrm{~mm}$ where $d$ is the actual diameter of the mild steel shank.

A nailing pattern to give maximum concentration of nails at maximum distance from the centre of rotation is based on minimum spacing of lod parallel to the grain and $5 d$ perpendicular to the grain.

The recommendations and findings in this paper are based on the use of dry $(16 \% \mathrm{~m} / \mathrm{c})$ radiata pine. Suitable nailing patterns for Douglas Fir to minimise split-

* Senior Lecturer, School of Engineering, University of Auckland.

** Consulting Engineer, Auckland.

*** Assistant Chief Structural Engineer Ministry of Works and Development, Wellington.

**** Structure's Engineer, Central Laboratories, MWD, Lower Hutt ting have not been developed. In addition the performance of this type of joint when nailed green and allowed to dry has not been studied.

\subsection{JOINT ACTION}

When a bending moment, axial force and shear force is applied to the members of the joint, forces are transferred from the timber into the steel plates by dowel action of the nails in the timber and by bearing of nails on the sides of the holes through the steel plate. The performance of the joint is thus directly related to the dowel action of the nails if yielding or buckling of the plate is prevented. The nails act in a similar fashion to rivets in a steel structure.

The derivation of basic working loads for laterally loaded nails is based on the 5 percentile of the load at $0.4 \mathrm{~mm}$ slip or the load at ultimate. This may be appropriate for strength considerations but stiffness is better predicted from the average load slip curve. Tests have shown (Fig. 3) that the stiffness of nailed joints under short term loading is high. The average slip of a $4 \mathrm{~mm}$ diameter nail under the basic working load is of the order of $0.02 \mathrm{~mm}$. Therefore the relative rotation between a $430 \mathrm{~mm}$ plate and a timber member, when the "average" load in nails is at the basic working load, is approximately $10^{-4}$ radians. The performance under long term loads is expected to be similar to that of other nailed structures.

\subsection{RESEARCH AND TESTING}

\subsection{Research at Auckland University}

\subsubsection{Portal Frame Tests.}

In mid 1978 two nail plate portal frame knee joints were tested. The laminated timber member size was $485 \mathrm{~mm}$ by $90 \mathrm{~mm}$ and $30 \mathrm{~mm}$ by $3.55 \mathrm{~mm}$ diameter galvanised bracket nails were used with $5 \mathrm{~mm}$ thick mild steel plates. Both joint failures were the result of outer timber laminates failing in tension at defects outside the steel plate region.

Later in 1978 another larger portal frame knee joint with $6 \mathrm{~mm}$ plates and $720 \mathrm{~mm}$ x $140 \mathrm{~mm}$ laminated timber members was tested. Failure was initiated by compression buckling of the nail plates when the steel plate maximum compression stress was approaching yield.

A $10.2 \mathrm{~m}$ span nail plate portal frame (2) has also been tested. The portal frame was loaded to failure under vertical loading. Portal frame dimensions and the BULLETIN OF THE NEW ZEALAND NATIONAL SOCIETY FOR EARTHQUAKE ENGINEERING, VOL. 14, NO. 4, DECEMBER 1981 


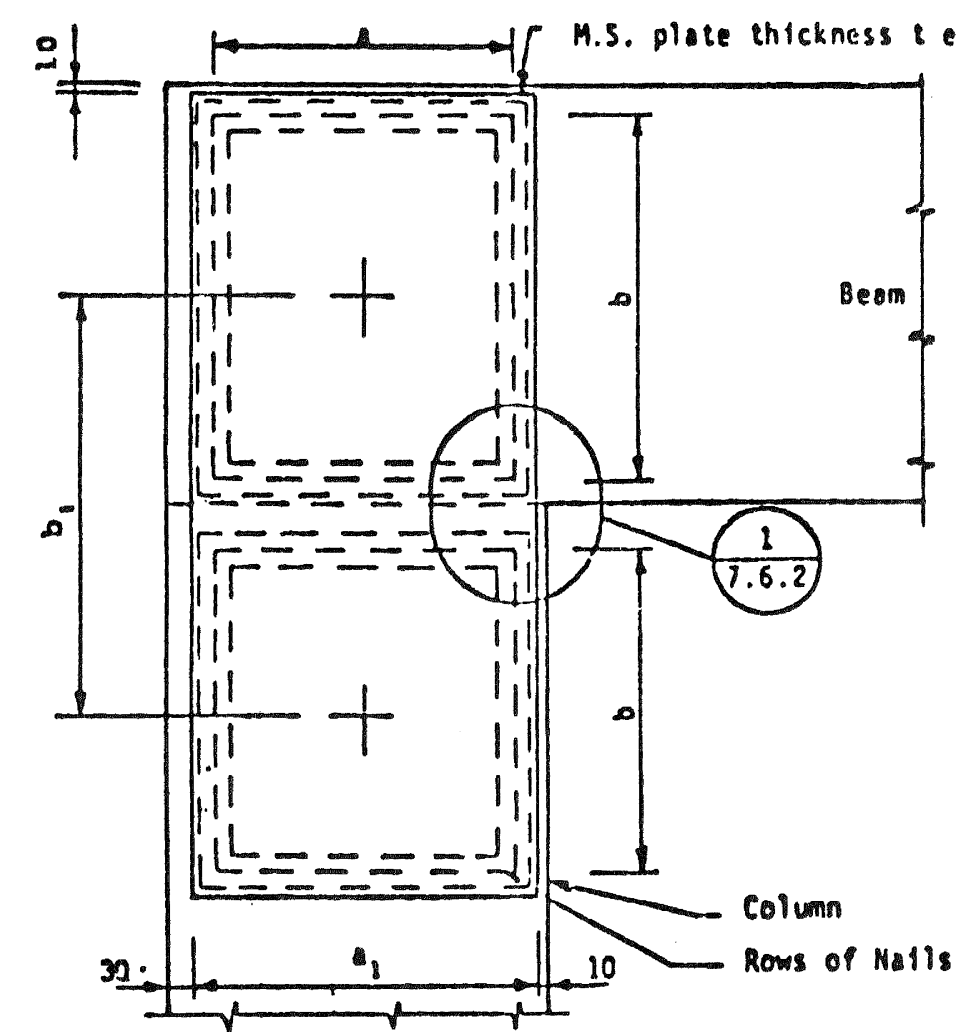

FIG. 1: ELEVATION OF BEAM-COLUMN

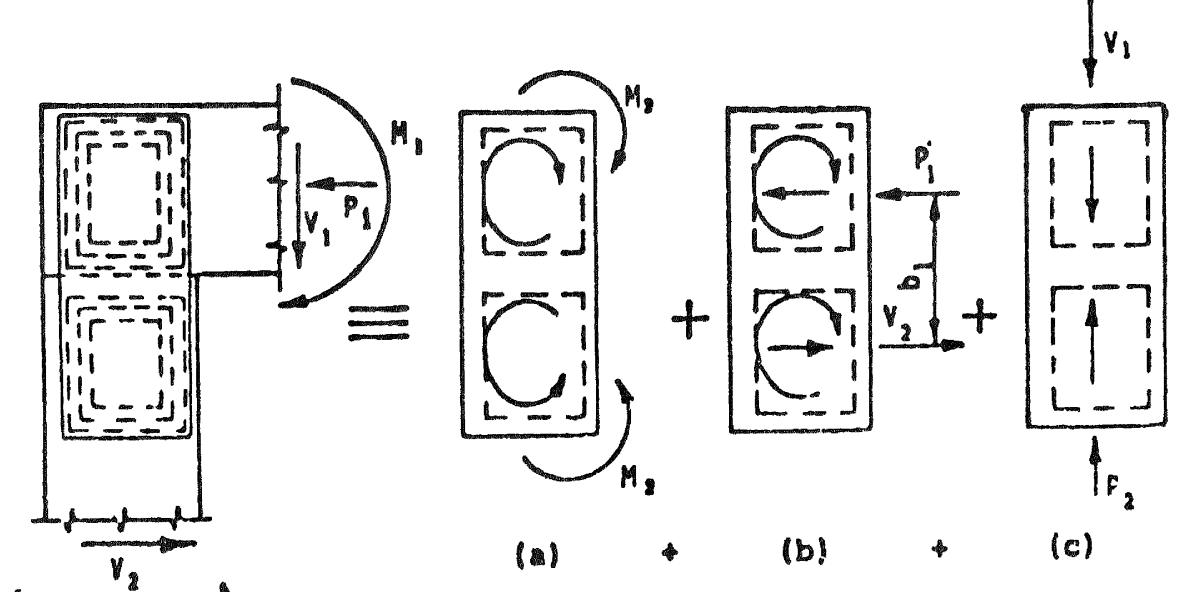

FIG. 2: JOINT FORCES

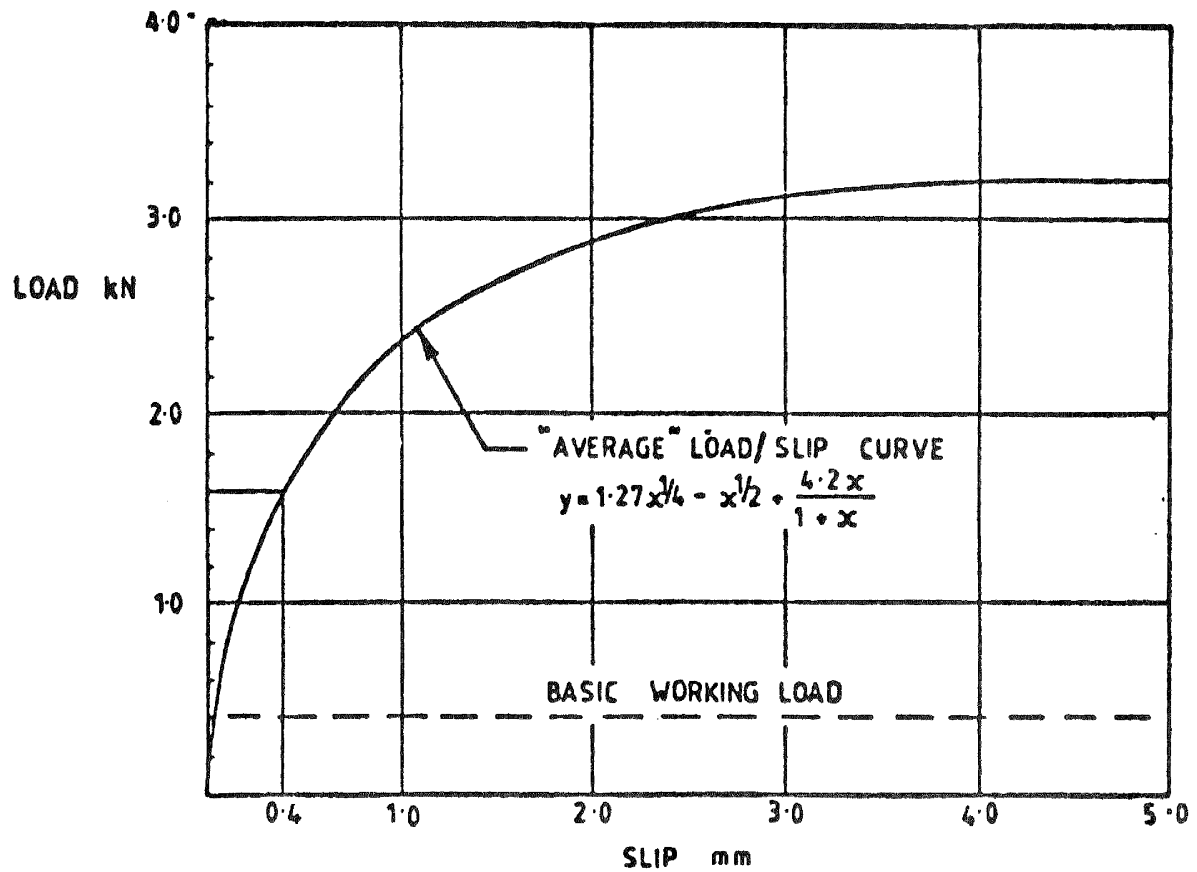

FIG. 3 LOAD/SLIP CURVE FOR 4.0mm DIA. NAILS UNDER LATERAL LOAD IN DRY RADIATA PINE 
loading system are shown in Fig. 4 and apex deflections and knee joint rotations are given in Fig. 5. Failure was initiated by the fracture of the laminated timber rafter just outside an eaves joint nail plate when the maximum timber stress was about $34 \mathrm{MPa}$ and the maximum nail plate slip was $1.3 \mathrm{~mm}$.

\subsubsection{Beam Tests.}

As the research for an M.E. thesis (3), a number of nail plate moment resisting joints were tested. Four different patterns of $30 \mathrm{~mm}$ by $3.55 \mathrm{~mm}$ diameter galvanised bracket nails were used and the number of nails was kept low so that the joints would fail by nail slippage with no fracture of the timber members. Fig. 6 shows the general test arrangements and a typical moment versus joint behaviour curve is shown in Fig. 7 .

A rivet group type analysis was applied and it was concluded that nails acting in a direction predominantly parallel to the grain carry approximately twice the load of nails acting perpendicular to the grain for a given slip at code values of nail loads but at ultimate all nails carry similar loads.

\subsubsection{Nail Tests.}

In mid 1979 a series of tests were initiated in which pairs of nails were loaded at various angles to the grain. This work is being continued to determine optimum geometries and types of nails.

\subsubsection{Summary.}

All the research has shown that nail plates can provide simple and effective means of making moment resisting connections between timber members. All tested nail plate joints have behaved satisfactorily and research is continuing in an endeavour to optimise details such as nail types, spacings and patterns.

\subsection{RESEARCH AND TESTING BY MINISTRY OF WORKS AND DEVELOPMENT}

\subsubsection{Test Program.}

Monotonic and cyclic shear tests were first performed on small nail-plate/timber connections to determine design nail loads. Three large beam/column ' $T$ ' joints were then cyclically tested under various moment/shear combinations, and the measured results compared with predictions from the small sample testing. A modified nailplate joint incorporating an energy absorbing and moment limiting joint plate, and the epoxy-resin repaired joint were also tested. Results are reported in full in references 4 and 5 .

\subsubsection{Selection of Nail Size and Nailing Pattern.}

Fifty millimeter long nails were driven through nominal $100 \times 50 \mathrm{~mm}$ radiata pine specimens to determine an optimum nailing pattern, a maximum nail diameter and minimum nail spacings such that minimum splitting occurred. Tests at Auckland University suggest less splitting occurs if nails are driven through nailplates, and no splitting was detected in the tests subsequently described using the selected nailing configuration with nailplates.

\subsubsection{Shear Tests on Small Nailplate Connections.}

The connections were monotonically or cyclically axially loaded such that the applied load in the nailplate was transmitted to the timber by shear in the nails. Tests were performed with the load both parallel and perpendicular to the timber grain. Timber densities and moisture contents were scattered over the range $370-540 \mathrm{~kg} / \mathrm{m}^{3}$ and $10-14 \%$ respectively.

\section{(a) Monotonic Tests Parallel to the Grain.}

Four failure modes were identified. although combinations did occur. The modes were: nails pulling out; nails shearing; internal timber shearing failure and timber tension failure (least common). The former two provided a very ductile response reaching $75 \%$ peak load at a displacement of $1.5 \mathrm{~mm}$ and peak load at about $9 \mathrm{~mm}$. Peak loads for the other modes occurred at displacements between 1.2 and lomm, with a rapid load decay after peak load. The average monitored peak load was similar for all failure modes, except for the case of nails pulling out which was $20 \%$ lower.

\section{(b) Cyclic Tests.}

A typical plot from the cyclic tests is shown in Fig. 8. At each successive new peak displacement the corresponding loads increase up to about $2 \mathrm{~mm}$. Cyclic peaks at greater displacement exhibit approximately constant load and the hysteresis loops past this deflection show severe pinching and low early stiffness.

Comparing least squares regression curves fitted to the monotonic and cyclic tests indicates that the monotonic curve is similar to the cyclic curve parallel to the grain, but the corresponding forces are $20 \%$ larger in magnitude than the curve perpendicular to the grain.

\subsubsection{Cyclic Moment and Shear Tests on Full Scale ' $T$ ' Joint.}

Two 450 by 140 laminated timber members were connected by nailplates to form a ' $T$ ' joint, thus simulating a typical exterior one way joint of a multi storey timber building. The joint was subjected to cyclic shear and moment loading, simulating seismic loading. Five full size tests at different moment/shear ratios were done. For testing purposes the beam was separated by $20 \mathrm{~mm}$ from the column, thus eliminating any joint strength enhancement due to bearing action. Nails used were $4.0 \mathrm{~mm}$ $50 \mathrm{~mm}$ long galvanised mild steel.

The average measured timber dry density was close to that obtained in cyclic tests on small units, although the moisture content was $25 \%$ higher.

(a) Basic Nail Plate Test. 

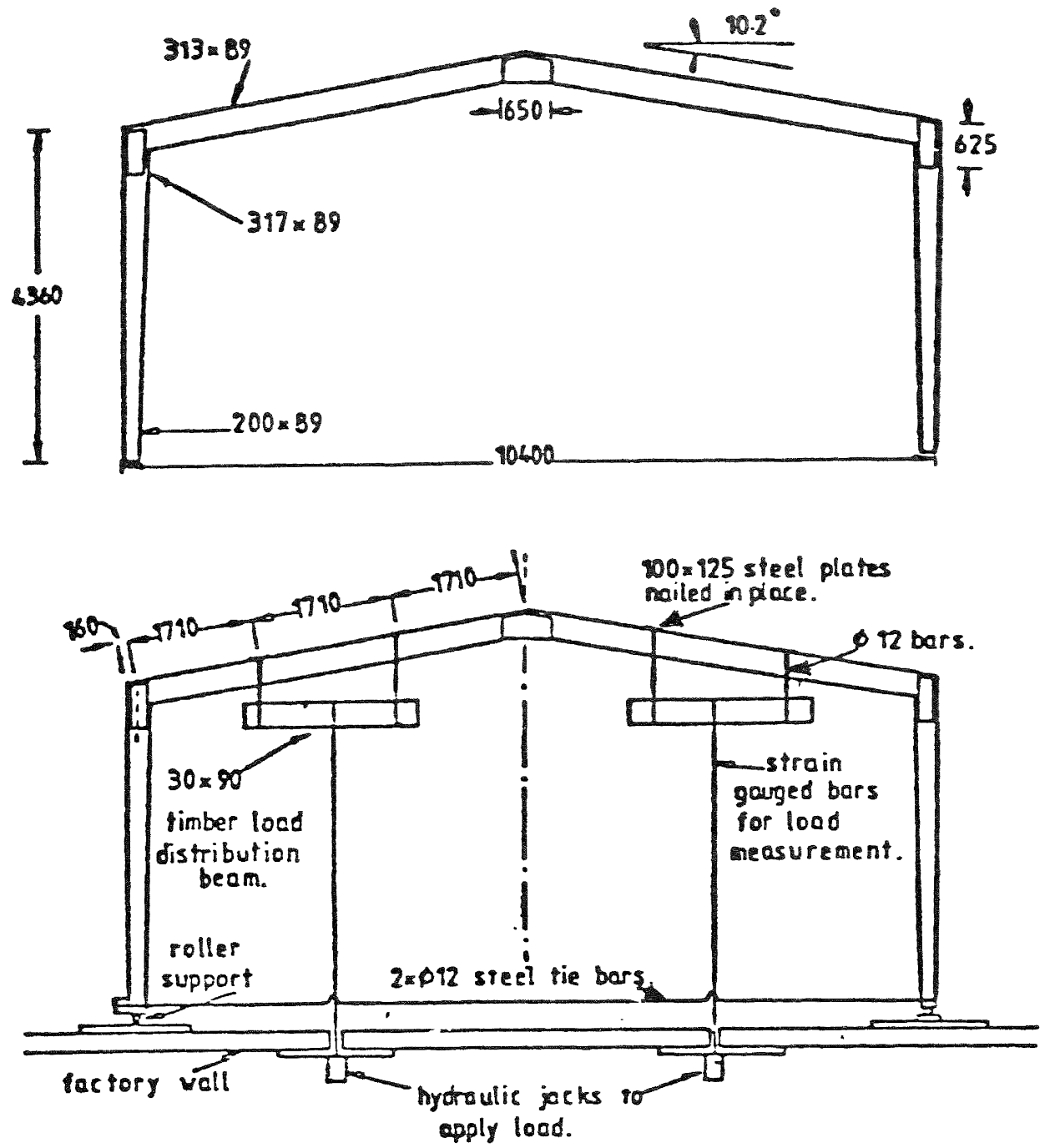

FIG. 4 PORTAL FRAME DIMENSIONS AND LOADING SYSTEM (FROM REF. 2)
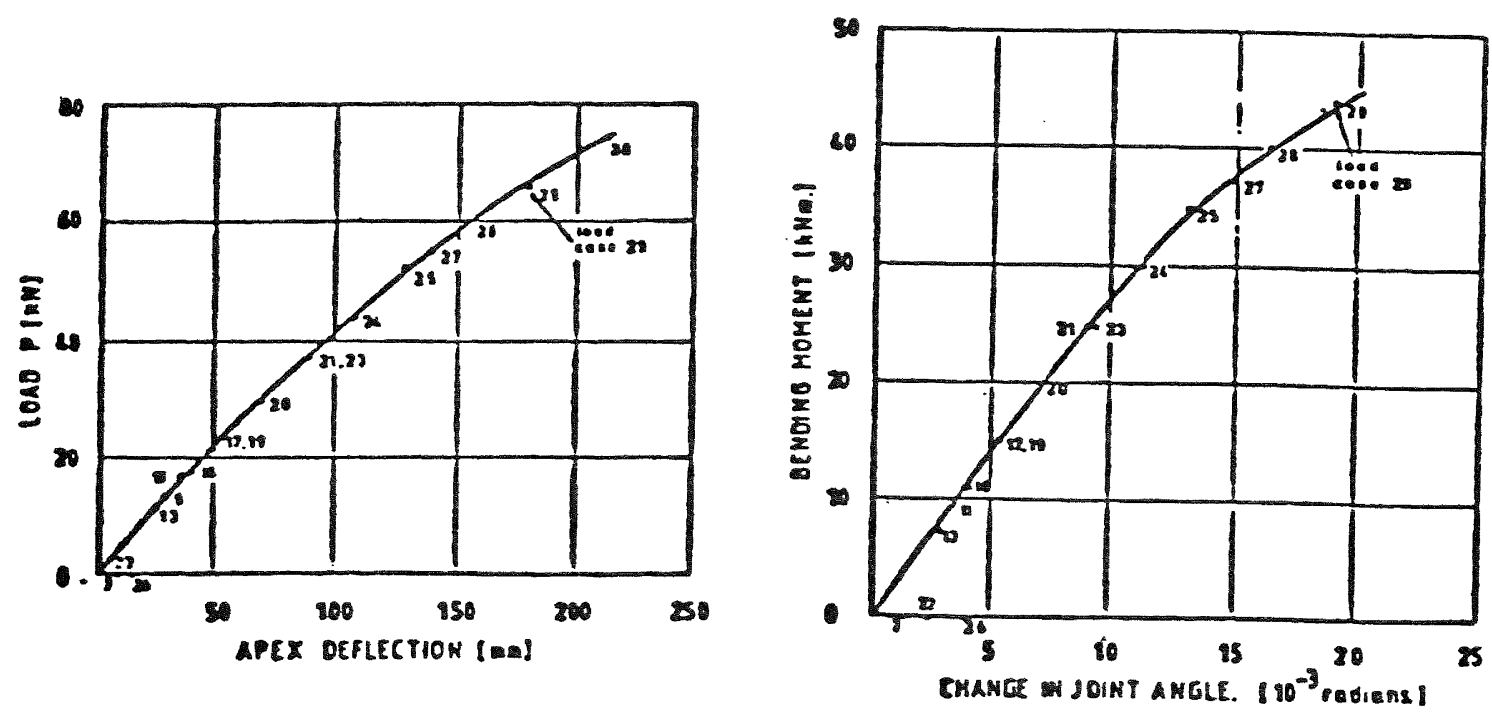

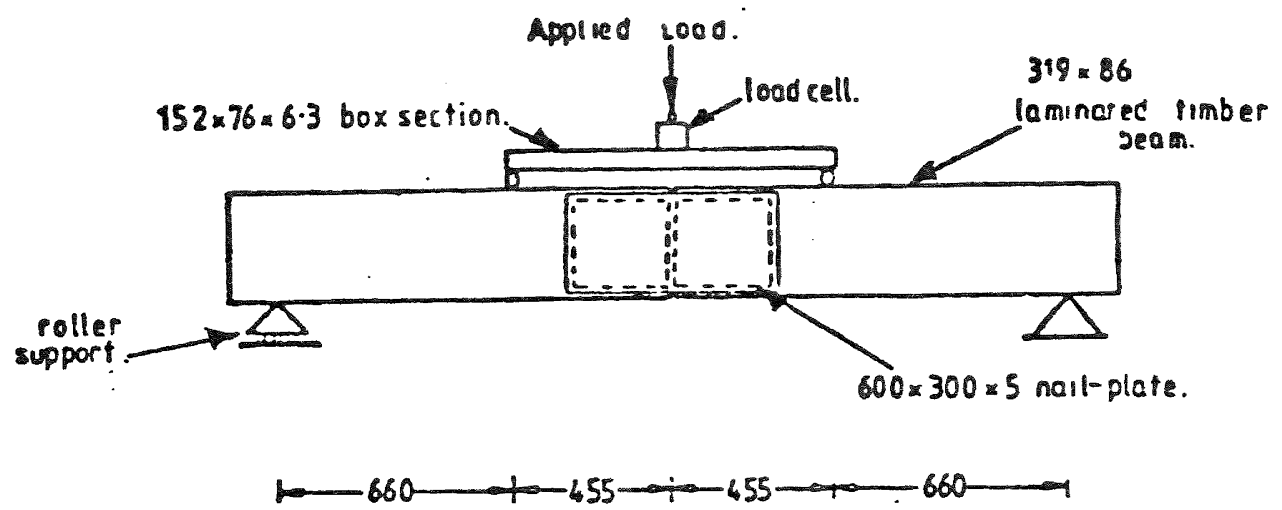

TEST TYPE 1.
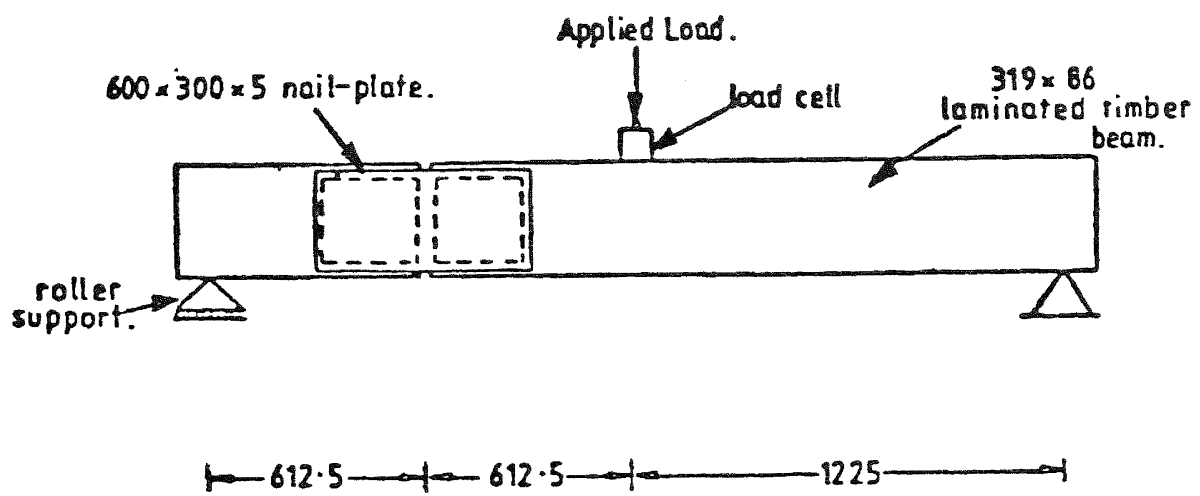

TEST TYPE ॥

FIG. 6 GENERAL TEST ARRANGEMENT (FROM REF. 3)

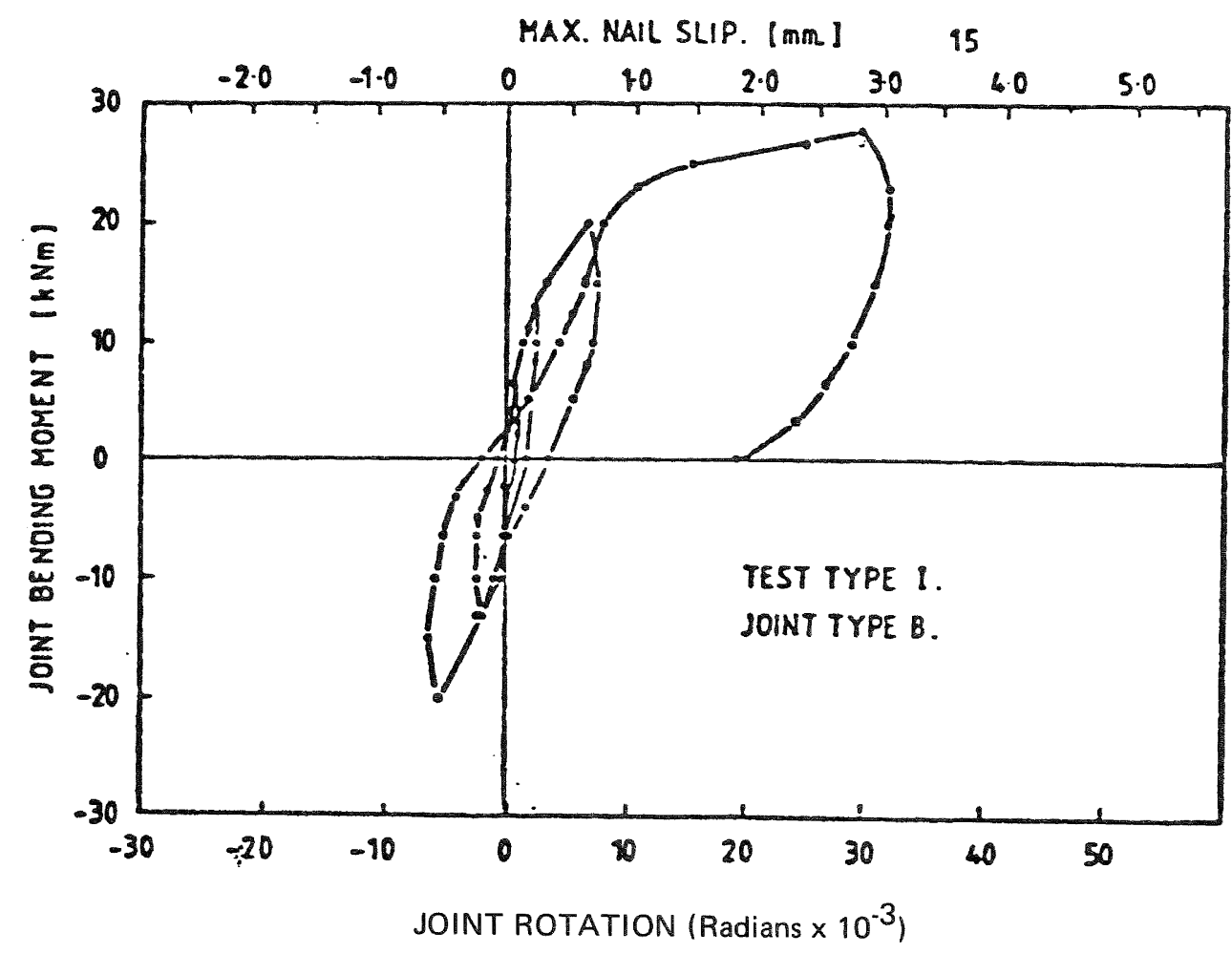

FIG. 7 ONE OF PRIME'S MOMENT VERSUS

JOINT BEHAVIOUR CURVES (FROM REF. 3) 
is shown in Fig. 9. The relative rotation and translation between the timber and nail plate was measured at $A$ and $B$, and $a$ typical plot for the rotation at $A$ is presented in Fig. 10. The hysteresis loops look similar to those obtained from small sample testing, and a theoretical curve linking peak points can be developed from the regression curves as illustrated in Fig. 11. Assuming rigid body movement of the nailplate, the assumed centre of rotation point 0 is adjusted until equilibrium is achieved at each rotation considered. The torsional resistance of the nail group about $0^{\prime}$ provides the moment $M$.

A comparison of the theoretical and experimental rotation at point $A$ adjusted for moisture content and grain orientation shows good agreement. A good approximation of the theoretical curve is obtained by assuming the centre of rotation 0 is at the centroid of the nailgroup $0^{\prime}$ thus simplifying the calculations.

(b) Test on Repaired Nailplate Joint.

Test four was cycled to a ductility factor of 19 (based on a ductility factor of 1 being assigned to a nailslip of $0.4 \mathrm{~mm}$ ). This is well above design seismic loading. The joint was repaired by epoxy resin injection technique using proprietary resin at $5 \mathrm{p} . \mathrm{s} . \mathrm{i} .(34 \mathrm{kPa})$. Because a glue bond between the nailplate and timber was not wanted in this particular test, the underside of each plate was coated with silicon grease before Test 4 .

After Test 5, the nailplate was removed, and it was found that glue covered $95 \%$ of the timber under the plate. No glue was bonded to the plate, and thus the greasing was effective.

The repaired joint was found to be significantly stiffer than measured in Test 4. At a relatively low displacement, (but higher load than the maximum recorded in Test 4 ) a split in the timber induced in Test 4 , but not subsequently repaired, extended and opened suddenly. The failure at this point can only indirectly be attributed to joint repair (the stiffening allowed a higher joint moment to be carried). The higher joint strength is probably due to glue seeping into deformed nailholes. Because the glue is stiffer than the timber, the slip between nailplate and timber is reduced. Thus, if the joint had not been so heavily worked in Test 4, the glue may have seeped less into nailholes and not given the same amount of increased stiffness. However, in practice the glue will cause a bond between nailplate and timber giving greater earlier stiffness.

(c) Modified Nailplate.

A modified nailplate was used to join the timber members consisting of a halfsize nailplate nailed to both the timber beam and column, and linked by a necked mild steel plate, welded to each nailplate. The dimensions of the necked zone were selected to ensure that it was flexurally weaker than the capacity of the nailplate/ timber connection. The strength of the joining plate thus limits the maximum joint moment, and protects the timber/ nailplate connections from damage under seismic attack.

Although large displacements were applied to the unit, no timber cracking was observed. The measured response was almost linear, with narrow hysteresis loops (small energy absorption) for cycles up to the theoretical first yield in the necked joining plate. this point fat stable hysteresis loops exhibiting no "pinching" effect were developed, showing little deteriorations on repeated loading.

\subsubsection{Conclusions.}

The basic nailplate joint was able to sustain large imposed rotations, with small (if any) drop in moment sustained at each successive (larger) applied rotation. Although the hysteresis loops were pinched, they still indicated large energy absorption within the joint. Measured peak loads agreed with predictions from small sample testing if adjustments for moisture content and grain orientation were made. Both experimentally and theoretically, varying the joint moment/ shear ratio had little influence on joint response. A tested nailplate joint was repaired by epoxy resin injection. The repaired joint was significantly stronger than the original joint.

A modified nailplate joint, effectively incorporating an energy absorbing device which limited maximum joint moment, provided fat stable hysteresis loops with no pinching indicating large energy absorption. The joining plate protected the nailplate/timber connection from damage.

\subsection{ANALYSIS}

\subsection{General}

A convenient analogy to use in determining the strength of a group of nails under the action of a torsional moment is to consider the stress on an area associated with each nail of magnitude $p \times q$ where $p$ is the spacing of the nails parallel to the grain and $q$ is the spacing of the nails perpendicular to the grain. The shear stress associated with such an area is $\mathrm{f}_{\mathrm{s}}=\mathrm{P} / \mathrm{pq}$ where $\mathrm{P}$ is the lateral load in the nail.

\subsection{Thin Walled Tube Analogy}

The shear stress at any point on the centre line of a thin walled tube is

$$
\mathrm{f}_{\mathrm{s}}=\frac{\mathrm{M}}{4 \mathrm{abs}}
$$

where $\mathrm{M}$ is the applied torsional moment $a$ is the centreline length of one side $\mathrm{b}$ is the centreline length of the other side

$\mathbf{s}$ is tube wall thickness (number of rows of nails multiplied by the spacing of the rows)

A rectangular ring of nails can be likened to a thin walled tube and under the action of an applied moment the approximate load in a nail can be determined 


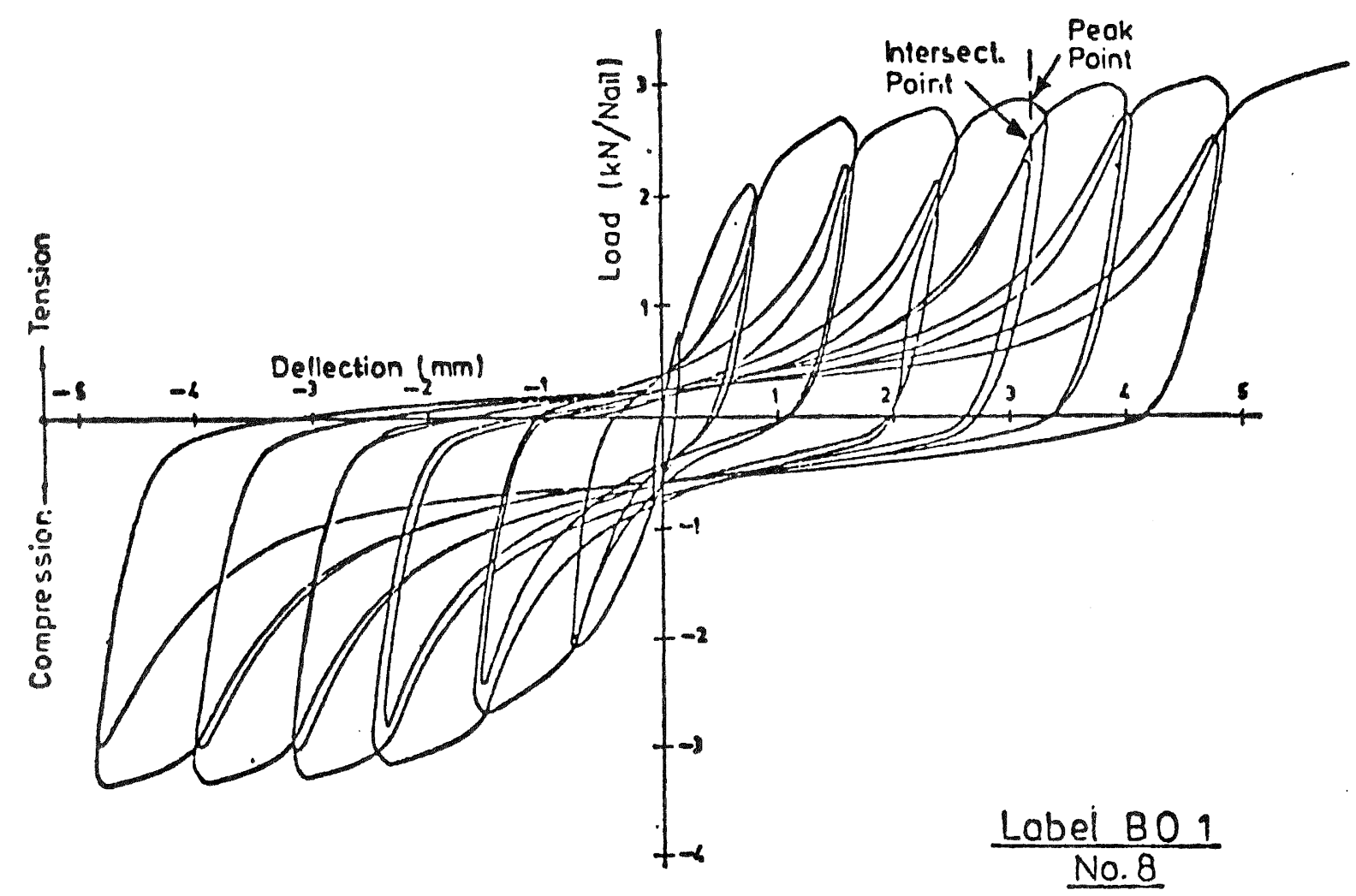

Fig. 8 Typical Load/Deflection Curve for Cyclic Loading Parallel to Timber Grain

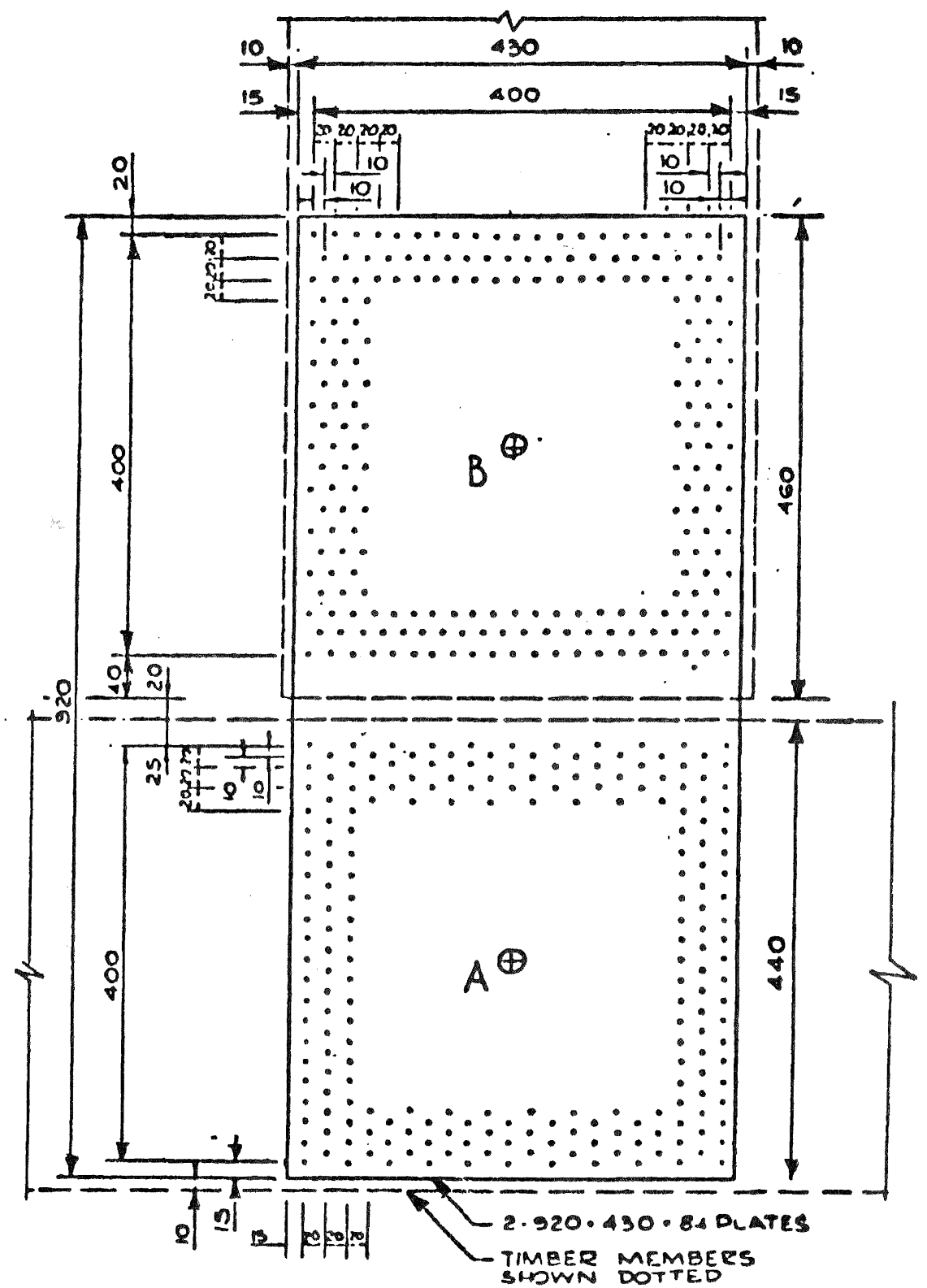

FIG. 9 NAILPLATE AND NAILING PATTERN USED IN TESTS 1, 2, 4 \& 5. 
from the "shear" stress. This analogy does not give a true description of the action of the nails since the shear stress is deemed to be uniform along the wall but gives a reasonable assessment of strength for wall ratios $(a / b)$ up to 2 .

\subsection{Rivet Group Analogy}

If each area pq associated with a nail is considered to be a "rivet" than it can be shown that the stress at any point in the rectangular ring of nails or "rivet group" is given by

$f_{s}=\frac{3 M c}{s(a+b)} 3$

where $c$ is the distance from the centroid of the group to the particular point on the centre line of the group.

This analogy gives a better description of the force in each nail and the line of action of the force than the thin walled tube analogy.

Since the load carried by each nail varies as the distance from the centroid it is convenient to compare the rectangular nail group to a circular nail group having an equivalent polar moment of inertia. The radius of this equivalent group is

$r=0.3(a+b)$

Therefore, the shear stress on the radius of the equivalent circle is

$f_{s}=\frac{0.9 M}{s(a+b)^{2}}$

and for a square group

$f_{s}=\frac{0.225 \mathrm{M}}{\mathrm{sa}^{2}}$

\subsection{Computer Analysis}

The force in each nail can be calculated using a force/deformation curve and equating the sum of these forces to the applied forces (5).

\subsection{DESIGN}

The maximum stresses occur at the junction between the two timber members with bending stress usually being critical. At this point the maximum distance between lateral restraining points is of the order of 15d (Fig. 3) and buckling of the plate will govern the design. Restraint against buckling may be provided by bolts through the joint or by stiffeners. The distribution of stress within the nail group is complex and in large joints restraint against lateral buckling should be provided.

The load carrying capacity of nails with diameters $3.15,3.55,4.00 \mathrm{~mm}$ increases by $25 \%$ with each increase in diameter and therefore costs of nailing should decrease with increase in size of nail.

Once the nail has been selected the nailing pattern can be determined. Approximate arrangements can be selected using Fig. 12

\subsection{SEISMIC PERFORMANCE}

The testing of full sized joints has demonstrated that the ultimate strength of a joint is controlled by

(a) bending strength of the timber member

(b) lateral strength of the nails

(c) buckling of the steel plate,

and all types of failure are difficult to predict with precision. In addition, the failure mode of (a) is brittle and there is little energy absorption. The failure associated with (b) is ductile but stiffness degrading where a predictable ductile behaviour is required the joint should be arranged so that tensile yield of steel can occur.

\subsection{FIRE PERFORMANCE}

Unprotected nail plates will deteriorate quickly in a fire and therefore where a fire resistance rating is required added protection must be applied. This added material should prevent the steel plate from softening and yielding and also prevent the nails from heating up to the point where they would cause the surrounding timber to char. Fire testing has not been carried out but fire tests proposed to be carried out at the Building Research Association of New Zealand to study the onset of charring of timber framing sheathed with various wall linings should give relevant information for this type of application.

\subsection{CONCLUSION}

The cost of the joint is closely related to the cost of drilling the plates. Various techniques are available among which are hand drilling of individual plates, computer controlled drilling and punching of plates. This latter method utilises a special die which encourages a shear break out on the reverse side of the plate.

Most structures are assembled on site. The majority of connections may be assembled on the ground but for ease of erection knee joints or beam-column joints are assembled half on the ground and half in place.

\section{SUMMARY}

Nail steel side plates provide an economical means of connecting timber members so that they may utilise their full bending strength. The joint is simple and may be applied in the field using unskilled labour. The high rigidity of the joint and simplicity of assembly make it possible for timber to compete with other materials in a wider range of structures.

\section{REFERENCES}

1. Bryant A.H., "Lamiplate portal knee joint tests" unpublished report for 

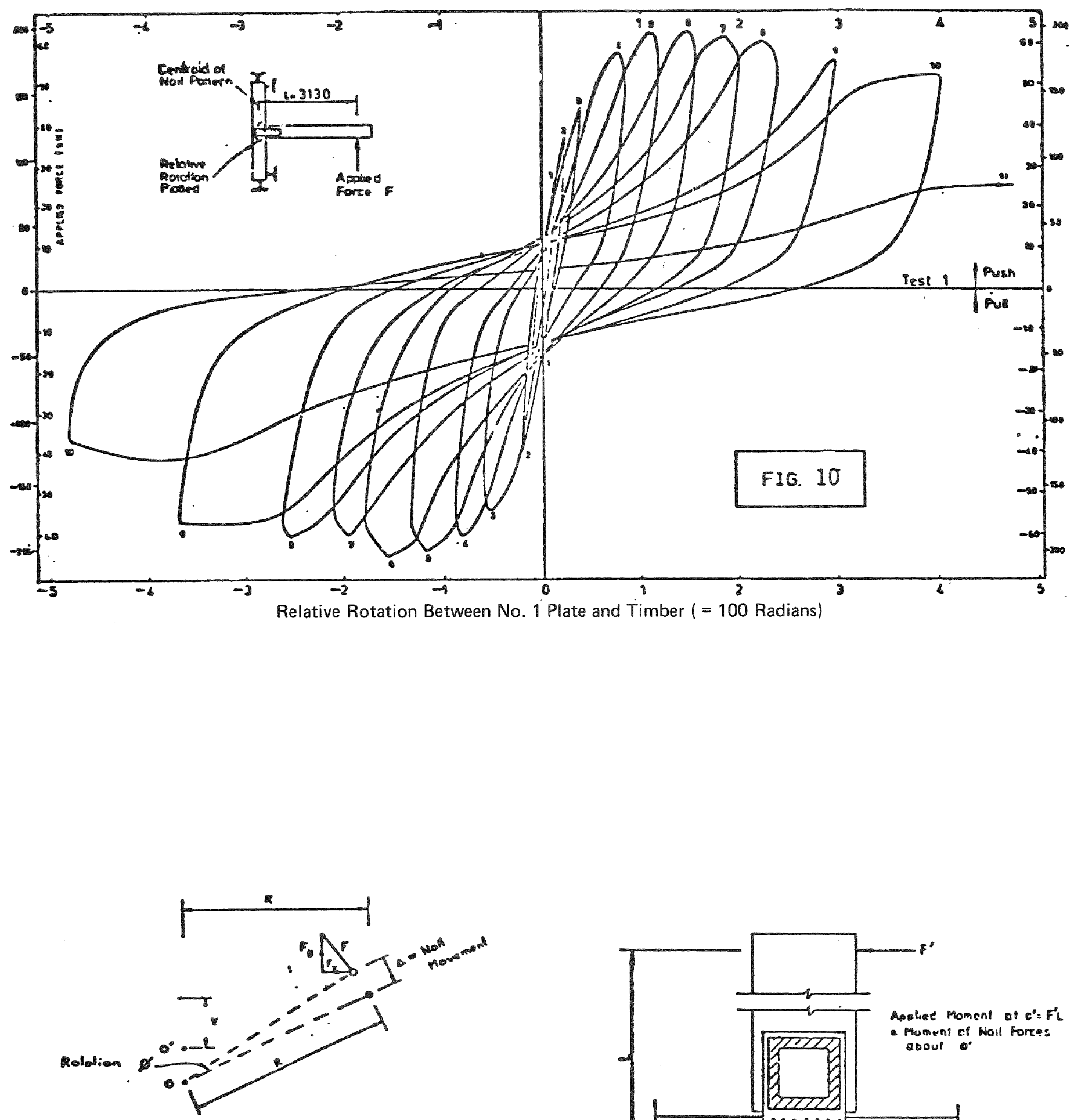

$\Delta=\mathrm{R} \phi$
$\mathrm{F}=1.266 \Delta^{0.25}-1.006 \Delta^{0.5}+4.204 \frac{\Delta}{1+\Delta}$

$M=\varepsilon F_{y} x+\varepsilon F_{x}{ }^{Y}$

$F^{1}=M / L \quad$ Adjust position $O$ until $\varepsilon F_{X}=F^{1}$

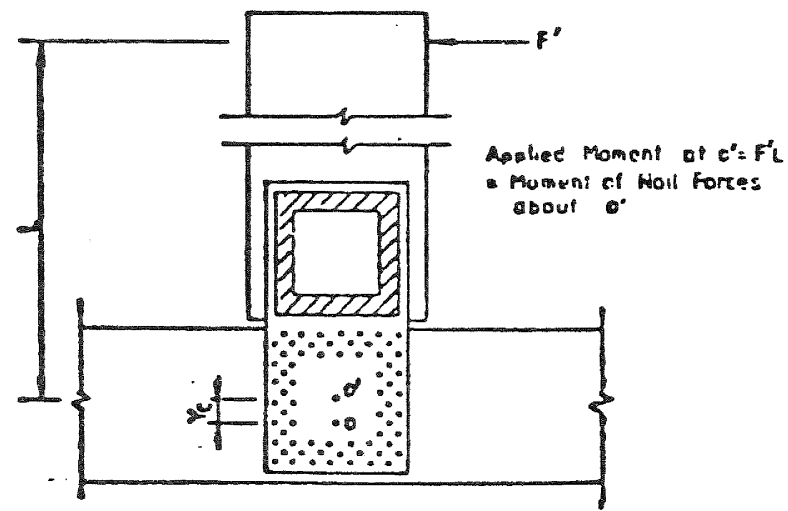

FIG. 11 ANALYSIS OF BASIC NAILPLATE 
J.A. Gibson, Gibson Laminates (1978) Ltd, July 1978.

2. Bryant A.H., "Lamiplate portal frame loading tests", unpublished report for J.A. Gibson, Gibson Laminates (1978) Ltd, September 1979.

3. Prime G.N., "Investigation of nailplate joints for timber members" Report No. 232, Department of Civil Engineering, University of Auckland, October 1980.

4. Thurston S.J. and Flack P.F., "Monotonic and Cyclic Testing of Timber Connections using Nailed Steel Side Plates", Ministry of Works and Development, Central Laboratories Report No. 5 - 79/7.

5. Thurston S.J. and Flack P.F., "Cyclic Loading of Large Timber Joints Incorporating Nailed Steel Side Plates", Ministry of Works and Development, Central Laboratories Report No. 5/79/6.

\section{PATENT APPLICATION}

Patent applications NZ Pat. App. No. 188054 (1978) and Aust. Pat. App. No. PE 3128 (1980) have been lodged in respect of the joint described in this paper and a royalty is payable for its use.

This is an edited version of a paper presented at the New Zealand Institution of Engineers Conference 1981.

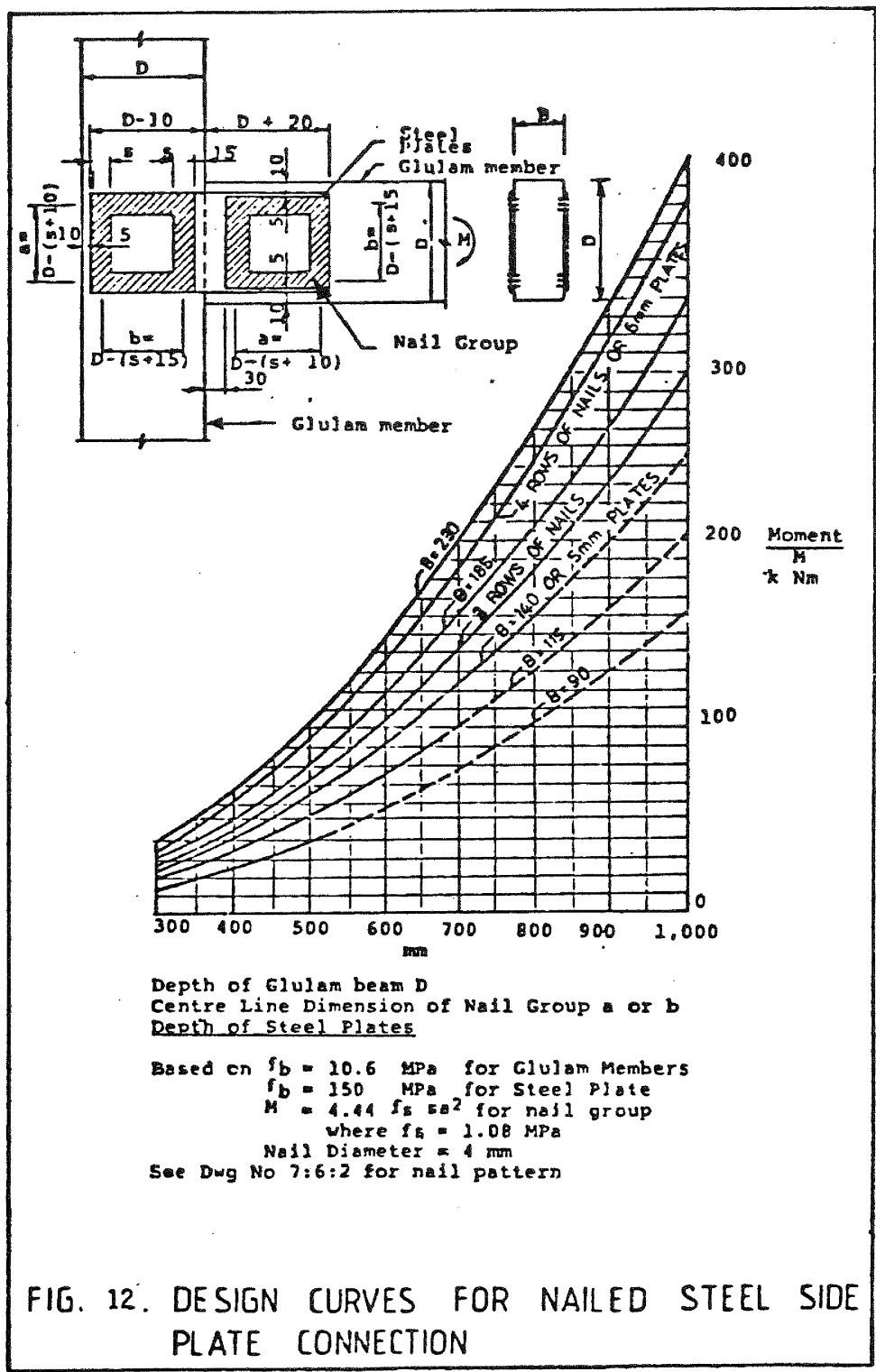

